Department of Animal Diseases,

Veterinary College, AL-Bath University, Syria.

\title{
SEROLOGICAL STUDIES OF PLEUROPNEUMONIA IN SHEEP AND GOAT FLOCKS IN ALEPPO AND REQA REGIONS OF SYRIA
}

(With 6 Tables)

By

\section{A. AL HAFEZ and Y. ALOMAR}

(Received at 10/12/2011)

$$
\begin{aligned}
& \text { دراسة مصلية لمرض التهاب الرئة والجنبة المعدي عند الأغنام والماعز في } \\
& \text { مناطق حلب والرقة في سوريا } \\
& \text { عبالستار الحافظ ، ياسر العمس }
\end{aligned}
$$

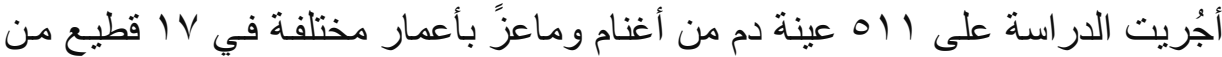

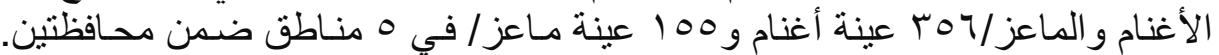

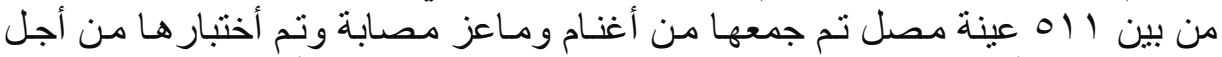

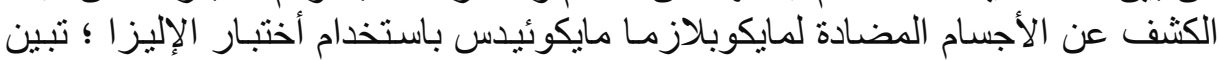

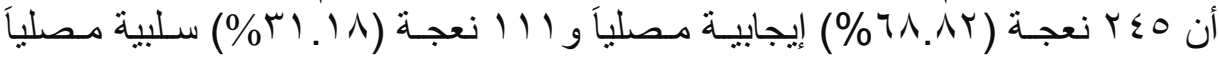

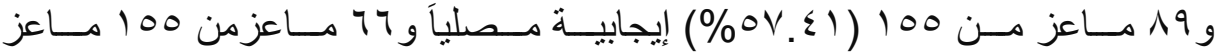

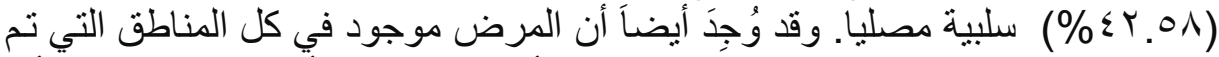

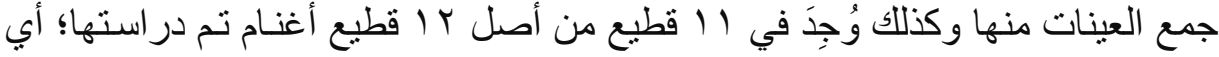

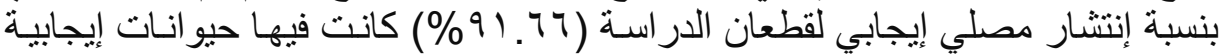

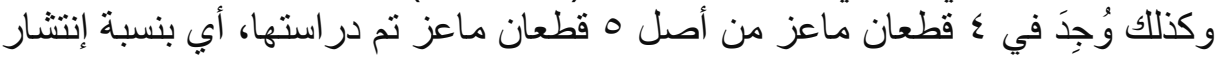

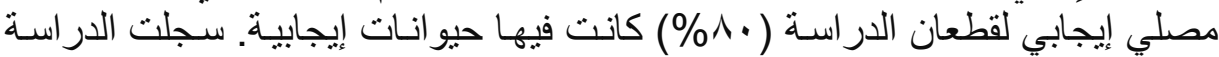
عوامل خطورة كامنة مر افقة للمرض كان من أهمها العمر الإنتاجي وحجم القطيع.

\section{SUMMARY}

The study was conducted on 511 Blood samples, Which were collected from suspected sheep and goat flock distributed in 2 province in different ages in 17 sheep and goat flocks /356sample of sheep and 155 sample of goat/ in 5 regions within tow province (mohafazat) the study was confirmed that the positive seroprevalence in 245/356 ewes was $(68.82 \%)$ wherease the study confirmed that the positive seroprevalence in $89 / 155$ goats was $(57.41 \%)$ and 111 ewes were reported negative 
reaction to ELISA test (31.18\%) and 66/155goats were reported negative reaction to ELISA test $(\% 42.58)$. The positive cases were reported in all study regions and the positive cases were reported in11Flocks of 12 study population sheep as seropositive percentage (91.66\%) Flocks level wherease goat positive cases were reported in 4 Flocks of 5 study population goat as seropositive percentage $(80 \%)$ flocks level. The major potential risk factors reported in the mentioned as study productivity age and flock size.

Key words: Pleuropneumonia, Mycoplasma mycoides, sheep, goat.

\section{INTRODUCTION}

مقدمـة

تسبب المايكوبلازمـا أمر اض ذات أنتشار واسع في كل من الإنسان والحيو ان

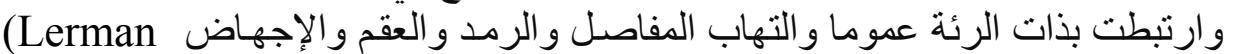
كـل مجموعـات and Beldjord, 1999; Fisher and Lerman, 1983) المايكوبلازما ممرضة و الأثوياء الأساسيون هم الماثية، الماعز و الأغنام، المايكوبلازما

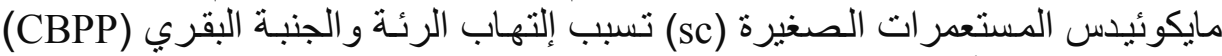

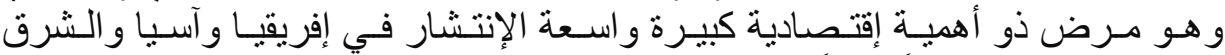

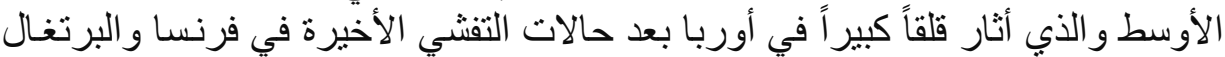

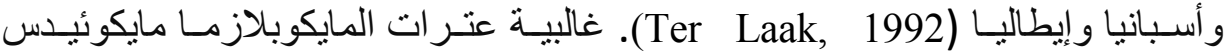

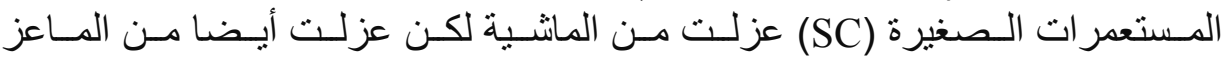

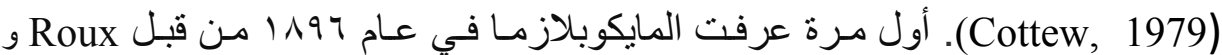

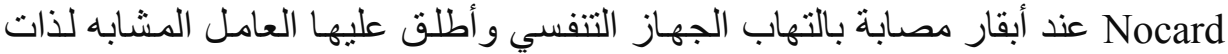
الرئـة (Pocard et al., 1896) (P.L.O) (أصـلا صنفت المايكوبلاز مـا كفيروسـات

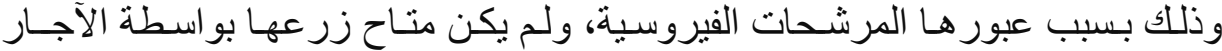

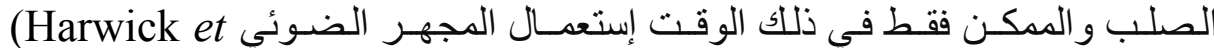
al., 1972 ; Eaton et al., 1945 ; Nocard et al., 1896; Goodburn (and Marmion, 1962

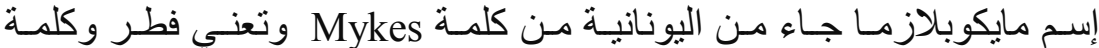

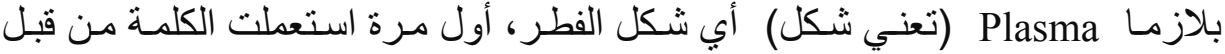
A.B.frank

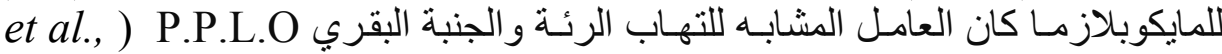

.(Edward 1956

المسبب هو مجموعة المايكوبلازما التي تشمل المفطورة ميكوئيديس تحت

النوع ميكوئيديس Mycoplasma mycoides subsp. mycoides ذات المستعمر ات 


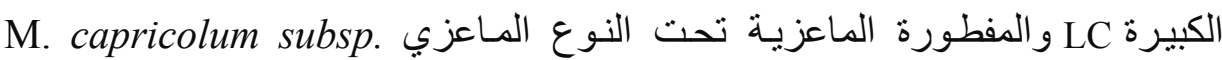
Mycoplasma mycoides والمفطورة ميكوئيديس تحت النوع المساعزي . Capricolum Bergonier et al., 1997) subsp. Capri

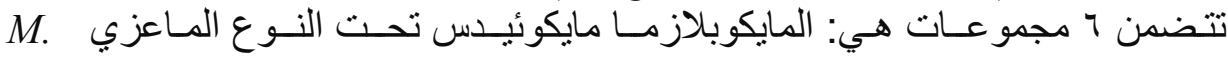
mycoides subsp. Capri مايكوري

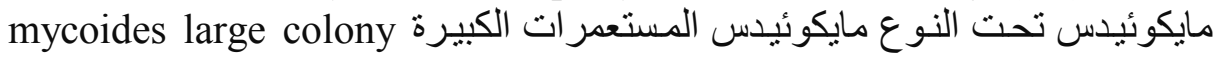

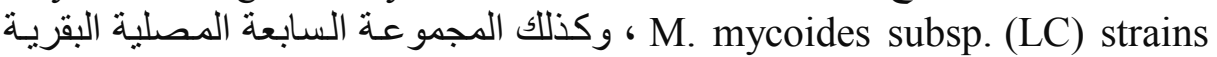
،M. capricolulm subsp capricolulm Bovine serogroup 7

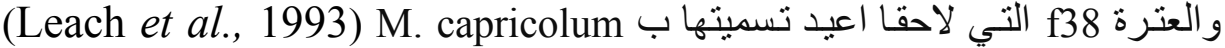
subsp. Capripneumonia

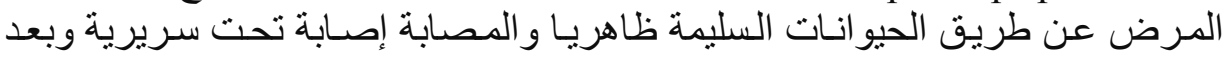

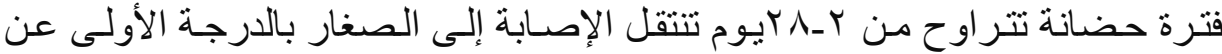

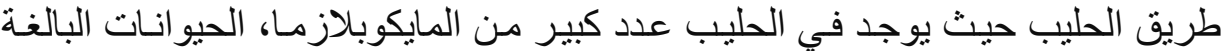

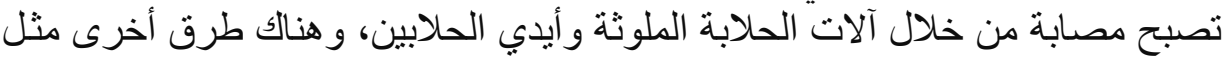

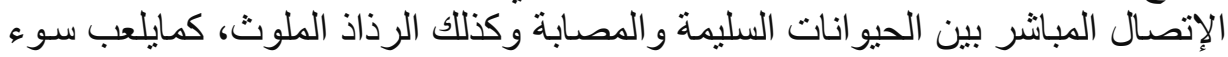

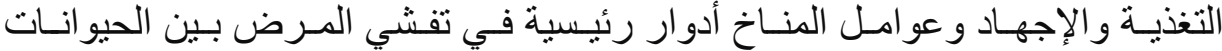

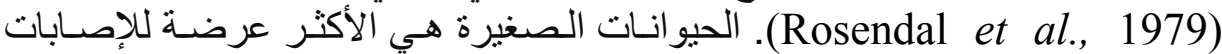

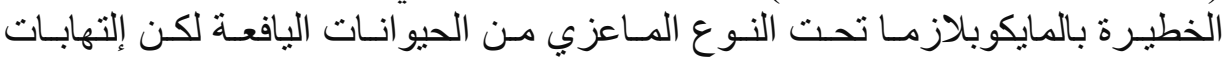

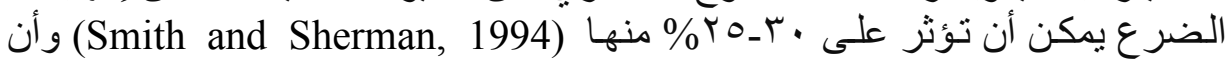

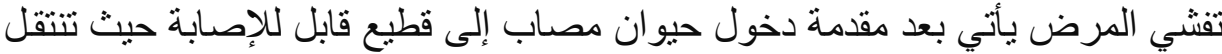

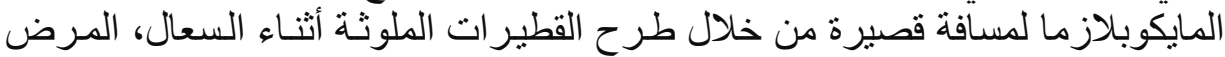

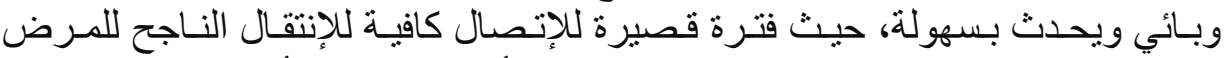
(Thiaucourt and Bo 1ske, 1996)

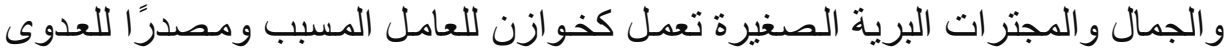

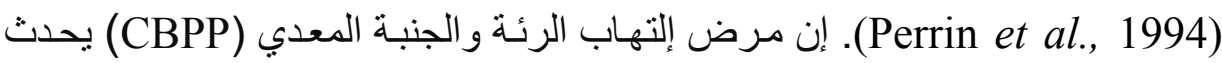

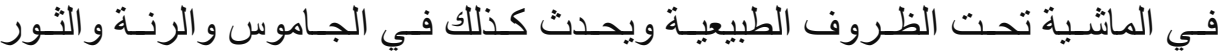

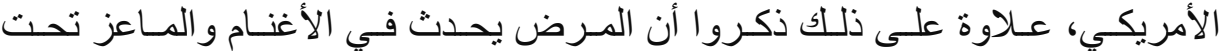

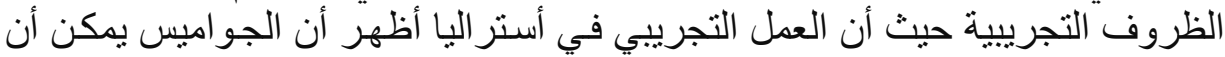

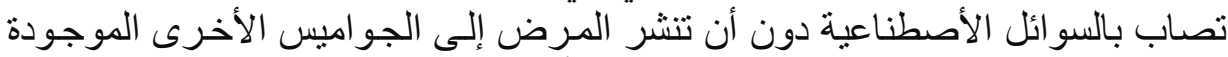

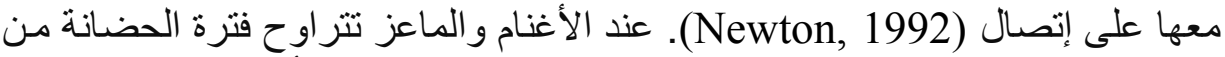

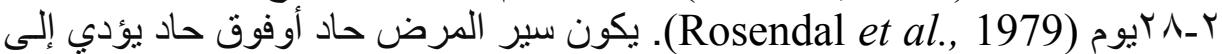

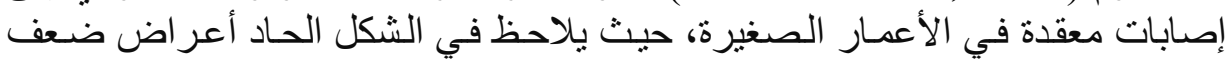

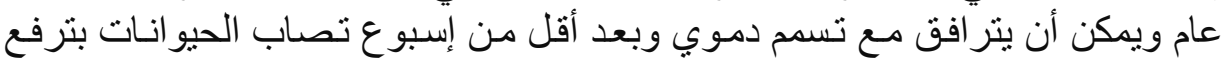

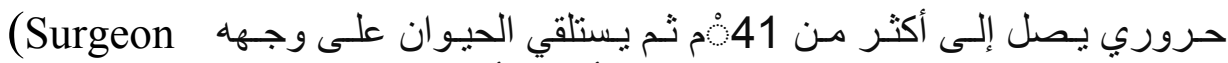

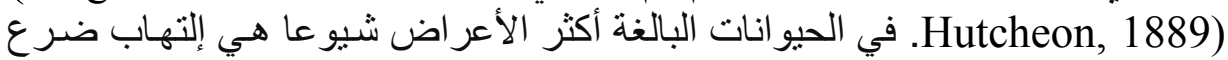


(Smith and Sherman, و إلتهاب رئوي جنبي و إلتهاب مفاصل قيحي و الإجهاض

الحيو انات الحوامل أو القريية من الو لادة يمكن أن تجهض بينما يموت بعضها

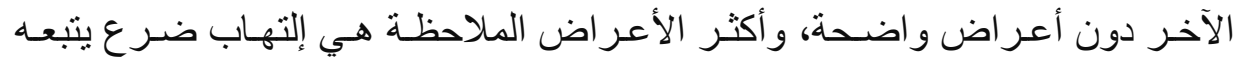

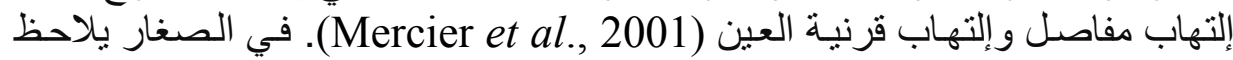

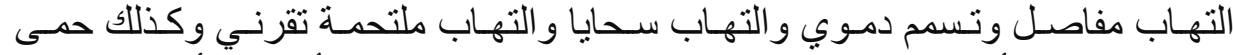
و فقدان للشهية و ألم حاد وتورم مفاصل واستسقاء وضيق تنفس و أغلب الأحيان الموت نتيجة التسمم الدموي (Nayak and Bhowmik, 1990).

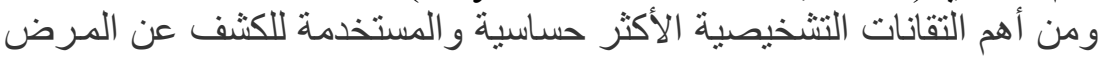

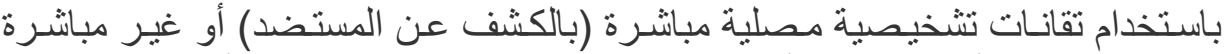

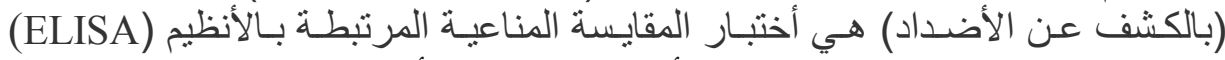
(Rodriguez et al., 1996a) البوليمير از التسلسلسي (Tola et al., 1997). (Polymerase Chain Reaction).

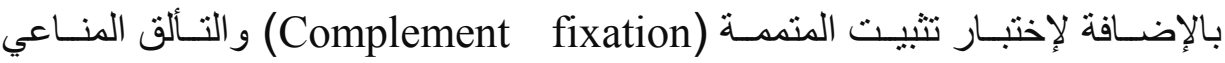
اللامباشر (Lefevre et al., 1987) .

\section{أهداف الدراسة Objectives of the study}

1 ـ تحديد انتشار المايكوبلازما في المنطقة الثمالية والثرائة الثرقية من سوريا

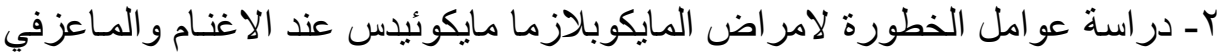
المنطقة الثمالية و الثرقية من سوريا.

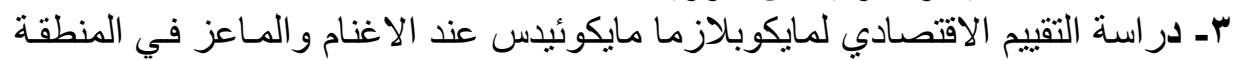

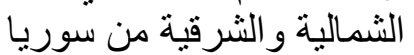
ع- وضع توصيات للتحكم و الوقاية من امر اض المن المايكوبلازمـا مايكوئيدس عند الاغنـام

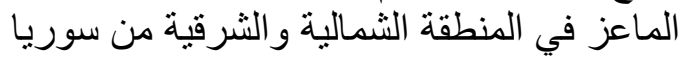

\section{MATERIALS and METHODS مواد وطرئق البحث}

مواد البحث : Materials

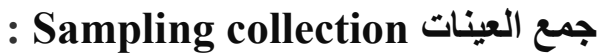

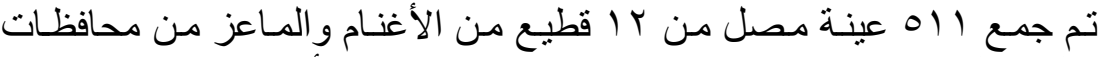

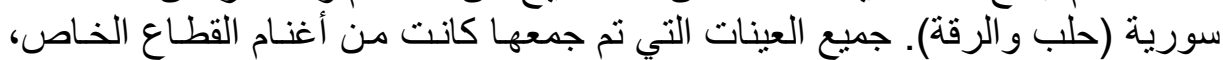

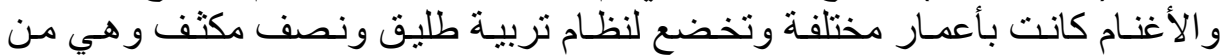

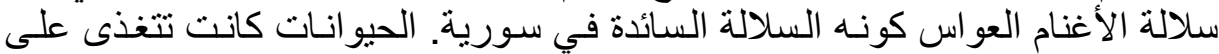

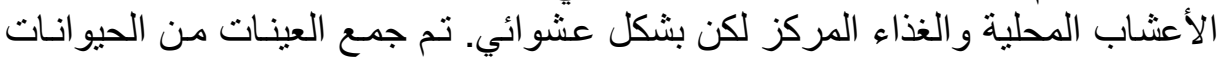

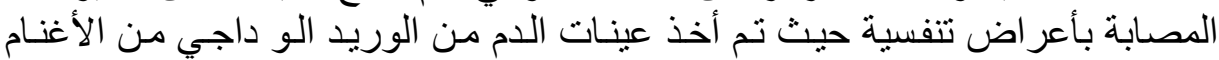




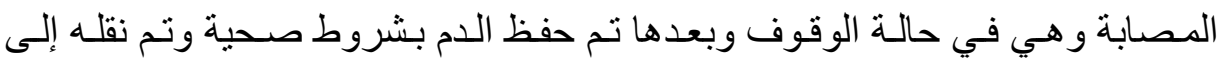

المخبر لفصل المصل وحفظه بدرجة حرارة - 20م حتى إجر اء الاختبار.

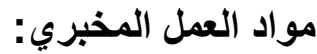

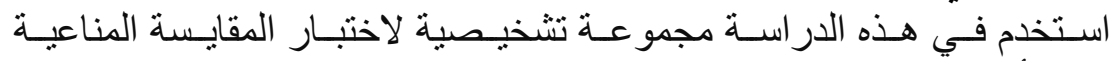

المرتبطـة بـالأظيج (ELISA) لـشركة

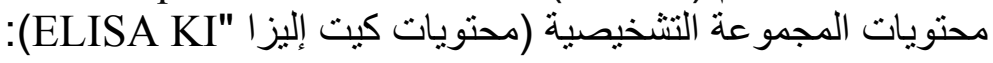

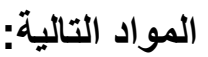

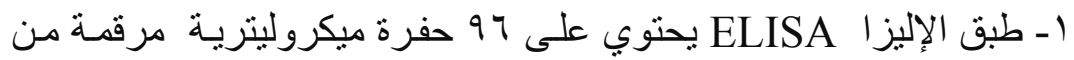

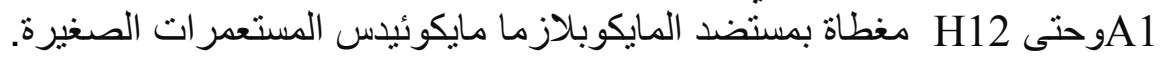

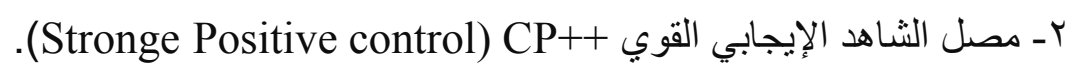

r- مصل الثاهد الإيجابي الضعيف CP+ (Weak Positive control )

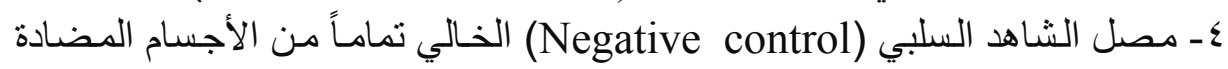

النو عية للمايكو بلاز مامايكو ئيدس المستعمر ات الصغيرة.

ـ محلول التمديد 24 (Dilution Buffer 24): يستخدم هذا المحلول من أجل مئل تمديد

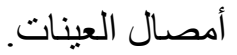

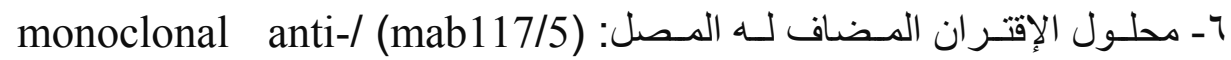

.(Mmmsc antibody

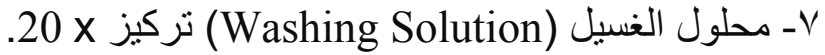

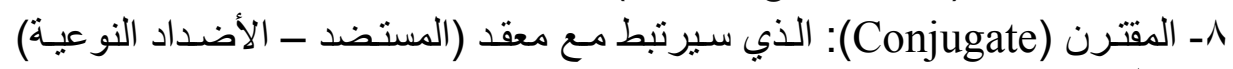

و المقترن عبارة عن Protein G peroxidase conjugate.

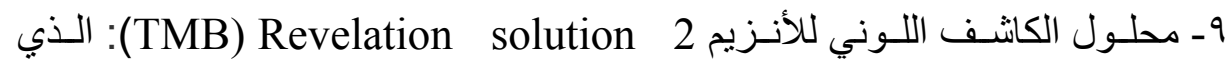

سيكثنف كمية الإرتباط بين محلول الإقتر ان المئن المرتبط بـالأنزيم ومعقد (المستضد -

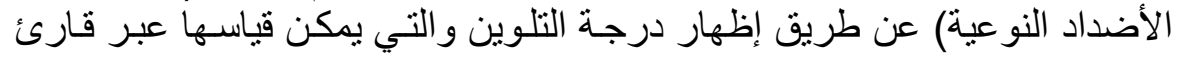

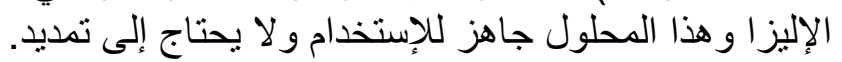

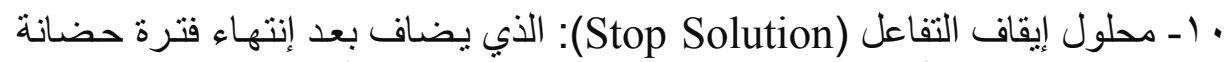

الكاشف اللوني للأنزيم لإيقاف و إنهاء التفاعل الحاصل (St)

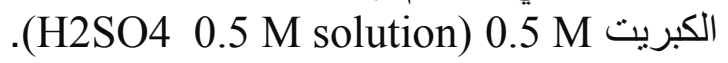

\section{طرائق البحث Methods:}

تم الكثف عن الأجسام المضادة النوعية للمايكوبلازمامايكوئيدس المستعمرات

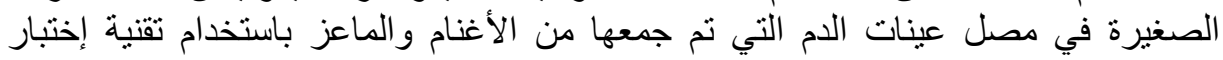
(Mycoplasma mycoides subspecies mycoides small ELISA الإليز colony(Mmmsc) kit, Pourquier Institute, France). 


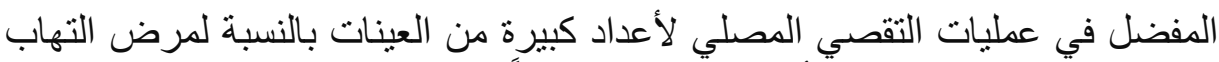

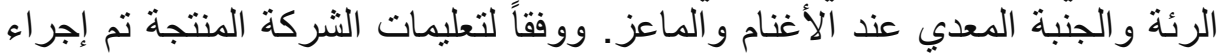

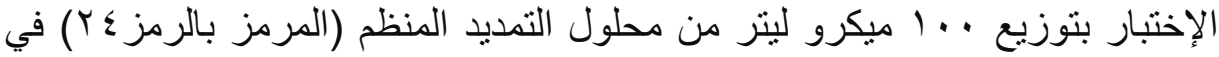

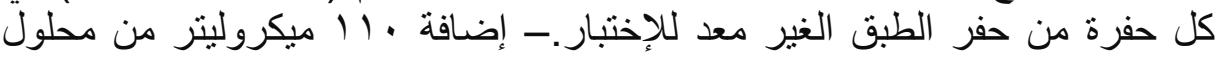

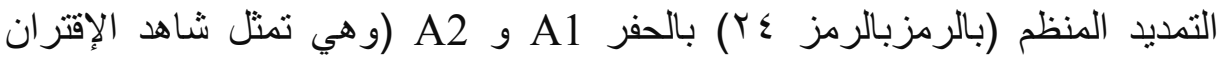

- إضافة ال ميكروليتر من الثواهد الثلاث CP1,B2,C1,C2 في الحفر CP++

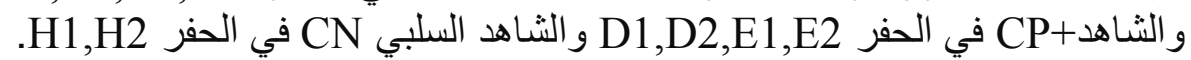
- إضافة | 1 ميكرو ليترمن كل عينة مصل ممددة إلى باقي الحفر من الحفرة A3 إلى الصى

- عملية دمج وتوزيع الأضداد وحيدة النسيلة 117/5: يمدد محلول الإقتران بنسبة

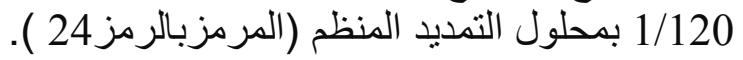

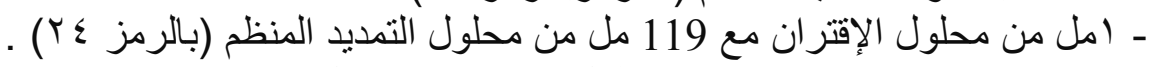
- يضاف • 11 ميكرو ليتر من محلول الإقتران الى كل حفر الطبق ماعدا الحفرة .A1,A2

- عملية تحضين المصل المضاف لله الأضداد وحيدة النسيلة. -نمزج باستخدام

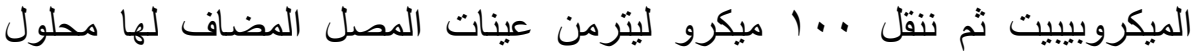

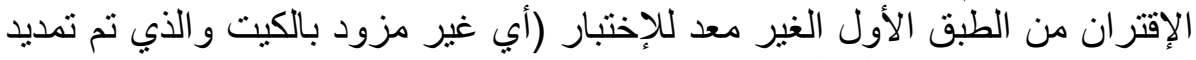

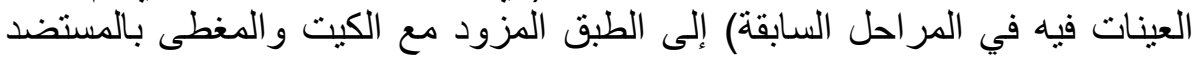

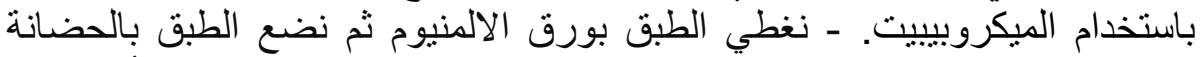

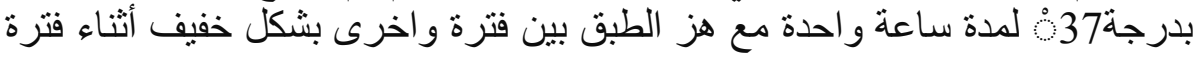

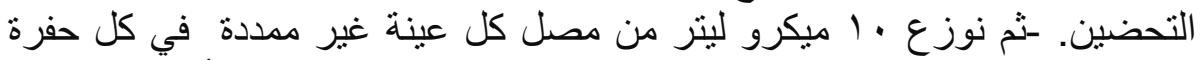

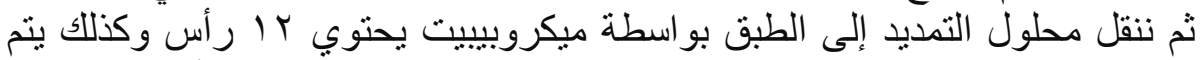

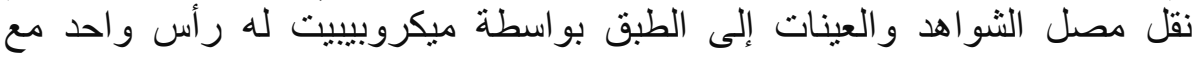

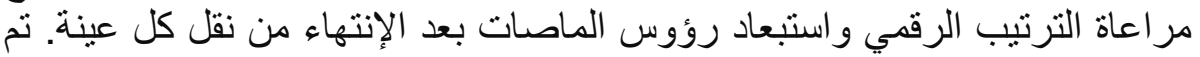

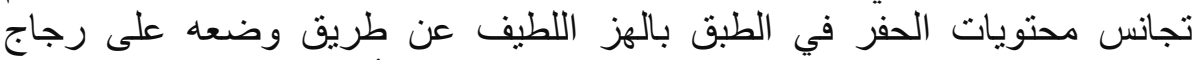

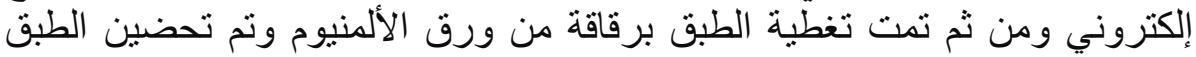

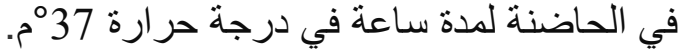

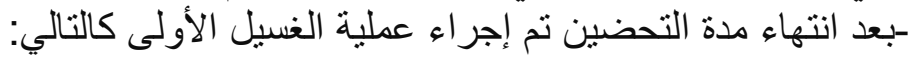

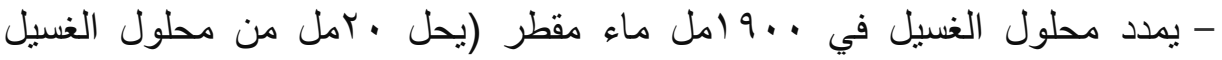

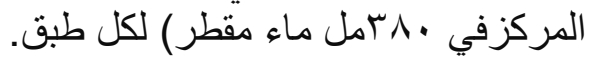

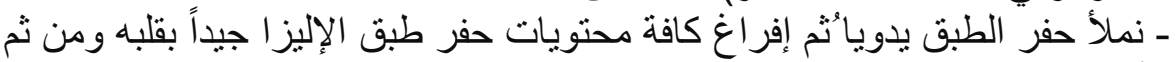

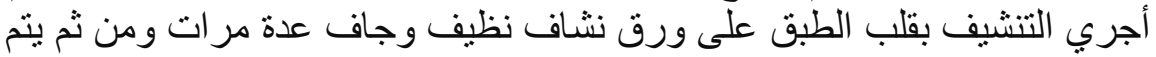

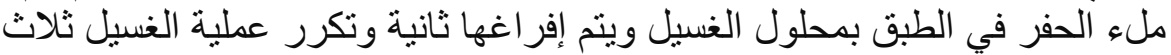

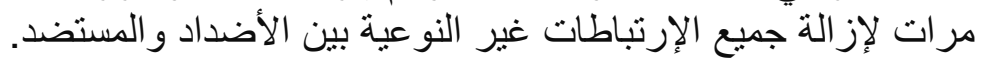




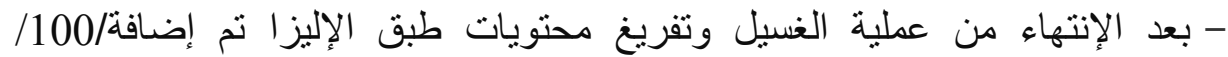
ميكروليتر لكل حفرة من محلول الإقتران الممدد بنسبة 1/100 من محلول الإنية التمديد (Dilution Buffer 24)

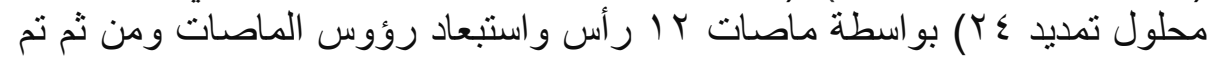

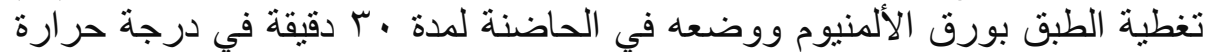
م. 37 - بعد انتهاء مدة التحضين تم إجراء عملية الغسيل الثانية كالتالي:

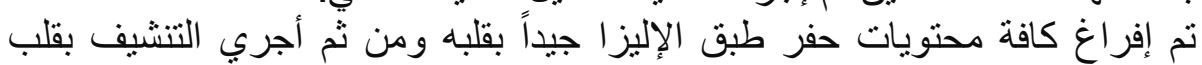

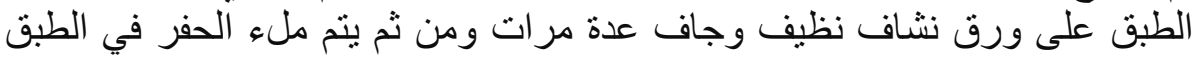

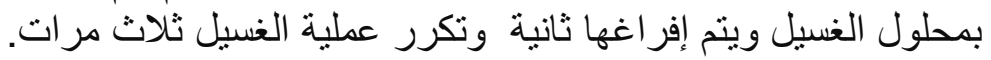

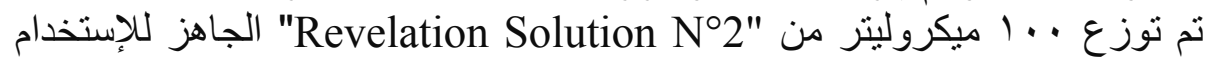

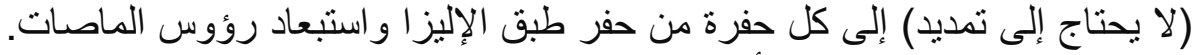

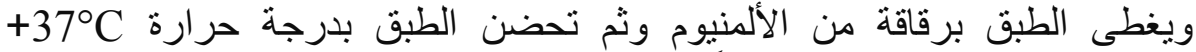

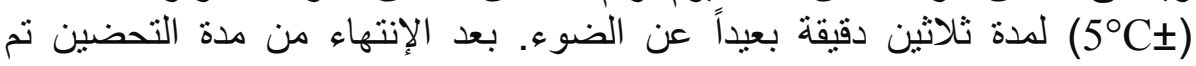

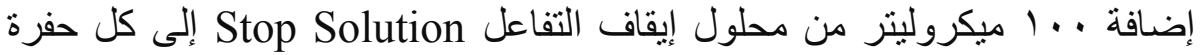
ومن ثم تم هز الطبق بلطف حتى يتجانس محلول التلوين ويجب المسح بحذب الطفر أسفل الطبق.تم قراءة نتيجة الإختبار على الطبق باستخدام جهاز قارئ الإليزا على طول الإنى

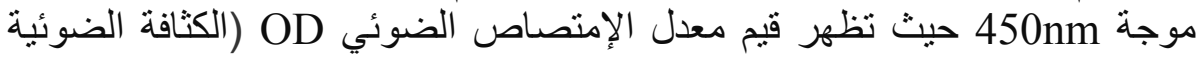
ELISA الكل حفرة من حفر طبق الإليزا Optical densities

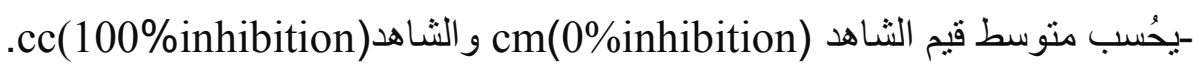
ثم حساب النسبة المئوية لكل عينة مصل كالتالي: PI=100x $\{($ ODCm-ODtest)/(ODCm-ODCc) $\}$ ـ تعتبر النتائج ذات دقة موثوقة حسب المعايير التالية:

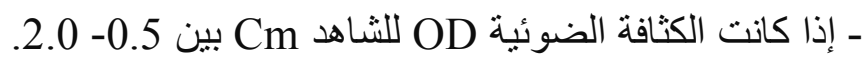

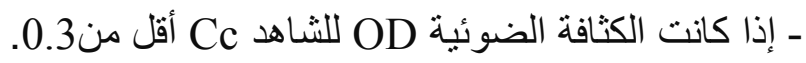

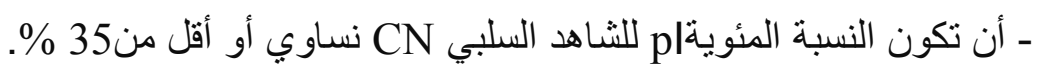

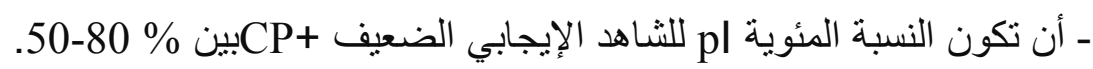

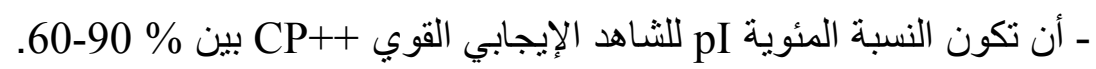

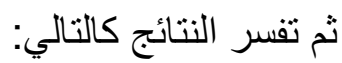

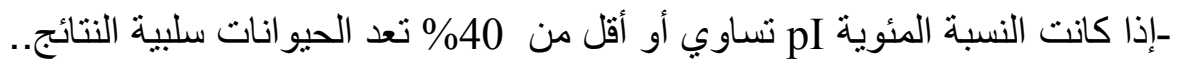

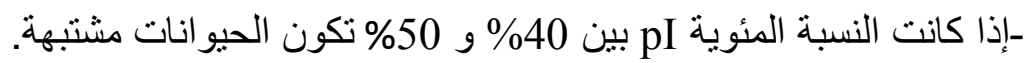

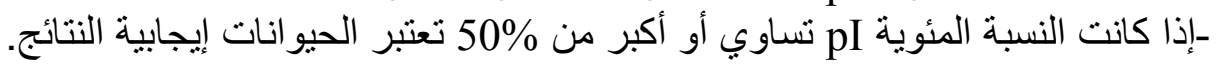




\section{RESULTS}

\begin{tabular}{|c|c|c|c|}
\hline معدل الإصابة النوعي & عدد الحيوانات & عددالحيوانات & العمرية/شئة \\
\hline
\end{tabular}

\section{النتنائسـج}

تم در اسة V ا قطيع أغنام وماعز في المنطقة الثمالية والثرقية في سورية في

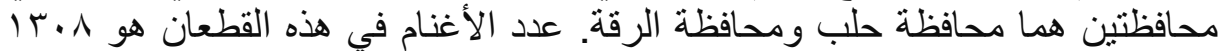

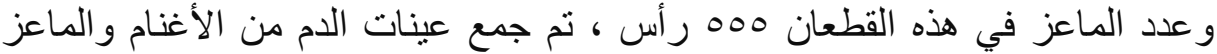

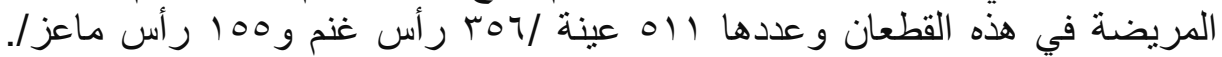
وتبين بأن معدل الإصابة عند الأغنام هو 27.21\% (356/1308) ومعدل الإصابة عابة عند

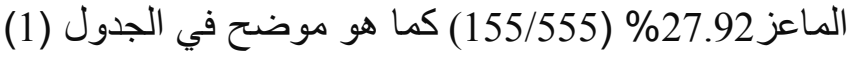

جدول (1): معدل الإصابة عند الأغنام في المنطقة الثمالية والثرقية من سورية.

\begin{tabular}{|c|c|c|c|c|}
\hline بالمايكو الإصلازمابة (النوعي) & عدد الحيوانات & الاغنـــــام & 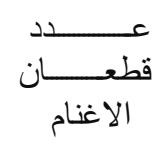 & المحافظة \\
\hline $26.54(253 / 953)$ & 253 & 953 & 9 & حلب \\
\hline $29.01(103 / 355)$ & 103 & 355 & 3 & 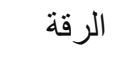 \\
\hline $27.21(356 / 1308$ & 356 & 1308 & 12 & المجموع \\
\hline
\end{tabular}

جدول (Y): معدل الإصـابة عند الماعز في المنطقة الثمالية والثرقية من سورية.

\begin{tabular}{|c|c|c|c|}
\hline 83.82 & 57 & 68 & $\geq 6$ \\
\hline 63.07 & 41 & 65 & 7 \\
\hline 65.92 & 147 & 223 & $8 \leq$ \\
\hline 68.82 & 245 & 356 & عمجمو \\
\hline
\end{tabular}


Assiut Vet. Med. J. Vol. 58 No. 132 January 2012

جدول (r): نسب الإنتشار المصلي للإصسابة بالمايكوبلازمـا مايكوئيدس حسب الفئة

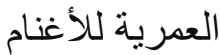

\begin{tabular}{|c|c|c|c|c|}
\hline $\begin{array}{c}\text { النوعي بالمايكوبلازما الإصابة } \\
\text { المعابة }\end{array}$ & العينات & الماعز & قالطعان & المحافظة \\
\hline $31.74(100 / 315)$ & 100 & 315 & 3 & حلب \\
\hline $22.91(55 / 240)$ & 55 & 240 & 2 & الرقة \\
\hline $27.92(155 / 555)$ & 155 & 555 & 5 & المجموع \\
\hline
\end{tabular}

جدول (؛): نسب الإنتشار المصلي للإصـابة بالمايكوبلازما مايكوئيدس حسب الفئة

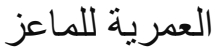

\begin{tabular}{|c|c|c|c|}
\hline بالمايكو بلازمابة النوع) & الايجابية مصليا & عددالحيو انات المختبرة & العمرية/شئة \\
\hline 0 & 0 & 26 & $\geq 6$ \\
\hline 0 & 0 & 0 & 7 \\
\hline 68.99 & 89 & 129 & $8 \leq$ \\
\hline 57.41 & 89 & 155 & المجموع \\
\hline
\end{tabular}

جدول (0): نسب الإنتشار المصلي للحالات الإيجابية وارتباطها بحجم القطيع عند

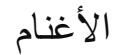

\begin{tabular}{|c|c|c|c|c|}
\hline 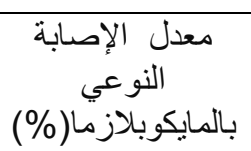 & الايجابيتمصليا الحيو انات & عددالحيو انات & القطعان/اغنام & حجم القطيع \\
\hline 0 & 0 & 0 & 0 & 75 اقل من \\
\hline 75.16 & 112 & 149 & 7 & $100-75$ \\
\hline 64.25 & 133 & 207 & 5 & 100 أكبرمن \\
\hline 68.82 & 245 & 356 & 12 & المجموع \\
\hline
\end{tabular}


جدول (†): نسب الإنتشار المصلي للحالات الإيجابية وارتباطها بحجم القطيع عند ماعز

\begin{tabular}{|c|c|c|c|c|}
\hline بالمايكوبلازمابة النو\%) & الإيجابية مصلياً & عددالحيو انات & عددالقطعان/ماعز & حجم القطيع \\
\hline 0 & 0 & 0 & 0 & اقل من 75 \\
\hline 39.62 & 21 & 53 & 2 & $100-75$ \\
\hline 66.66 & 68 & 102 & 3 & 100 أكبرمن \\
\hline 57.41 & 89 & 155 & 5 & المجموع \\
\hline
\end{tabular}

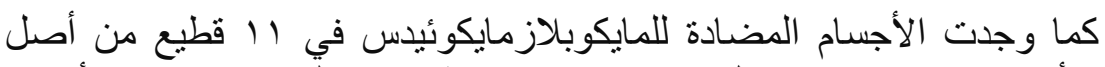

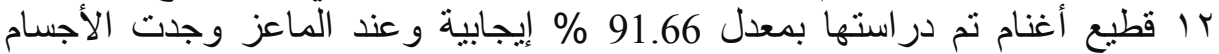

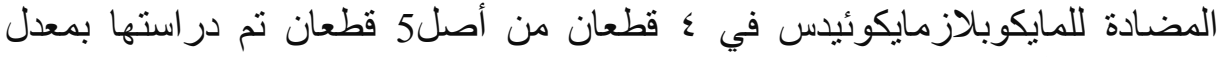

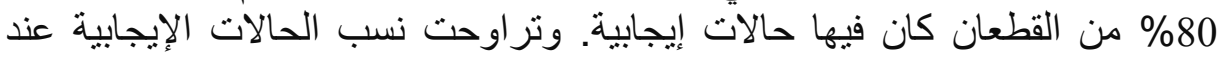

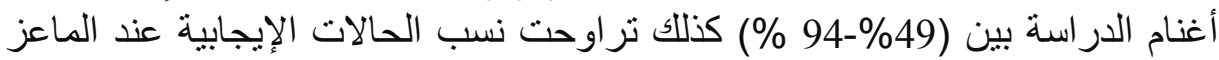

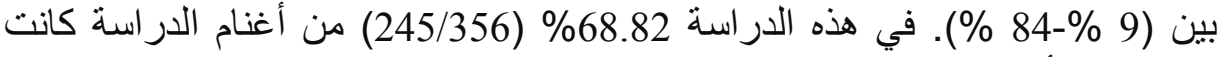

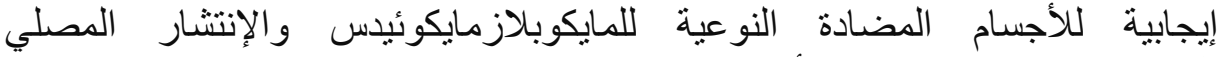

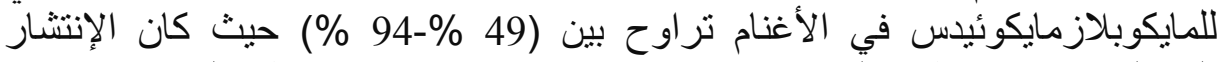

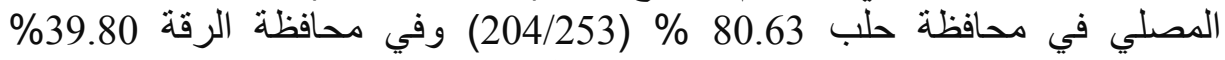

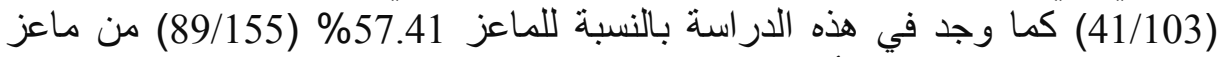

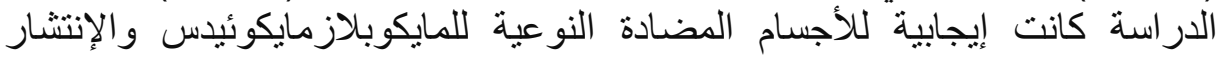

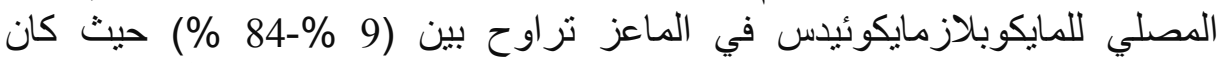
الإنتشار المصلي في محافظة حلب 84\% (84/100) وفي محافظة الرقة

التحليل الإحصائي Statistical Analysis:

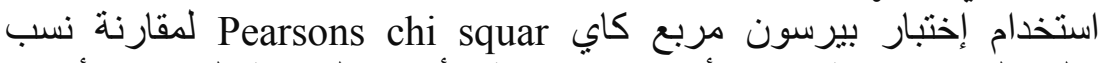

الانتشار المصلي الإيجابية مع الأعمار الإنتاجية لأغنام الإبية الإنة الإنة لتحديد الأعمار

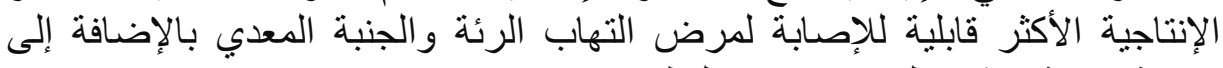

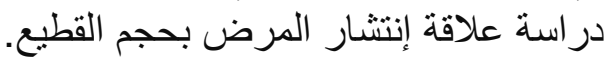

\section{DISCUSSION and CONCLUSION المناقثــة والإستنتاجـات}


تعد الأمراض التنفسية من الأمراض المستوطنة في الجمهورية العربية

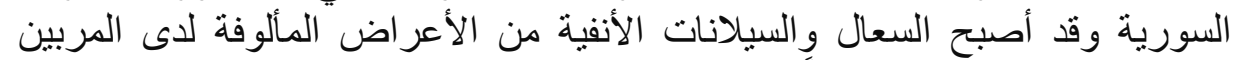

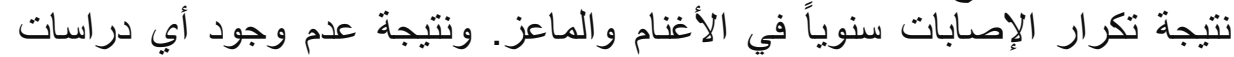

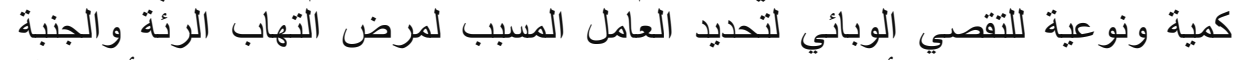

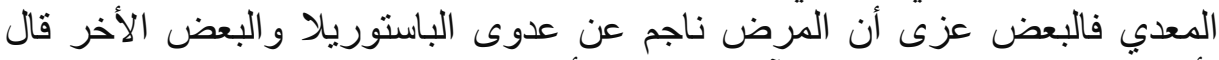

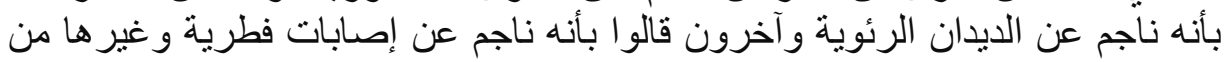

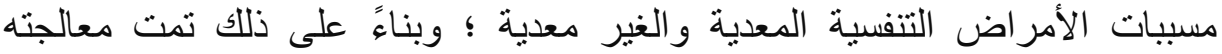

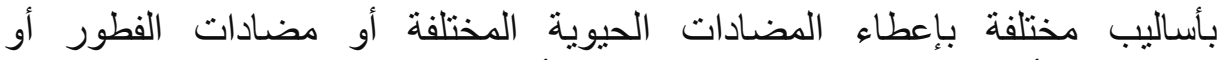

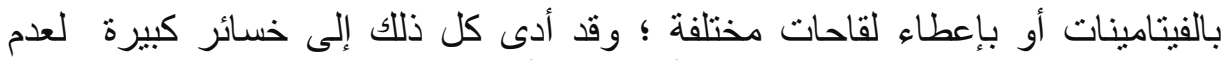

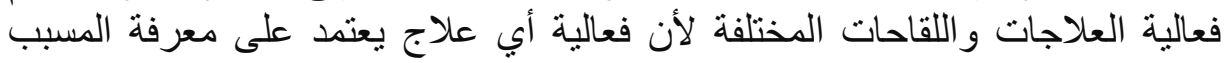

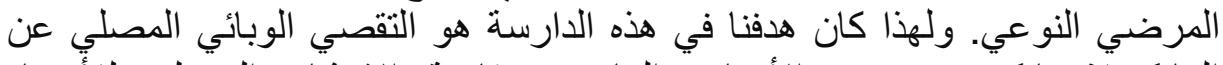

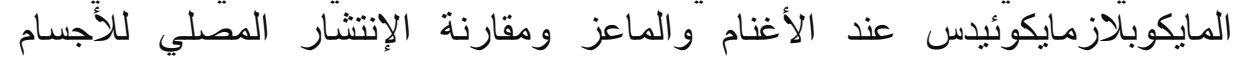

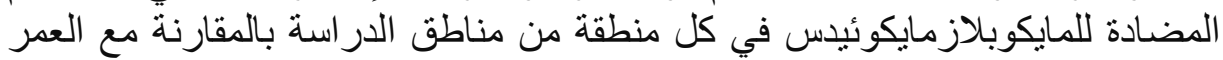

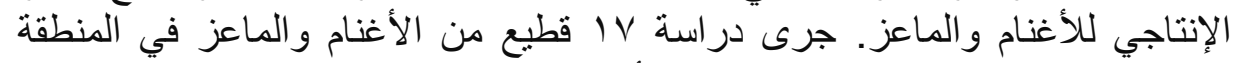

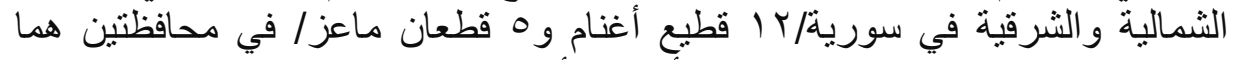

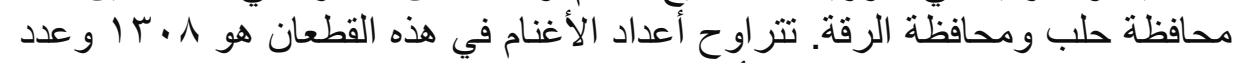

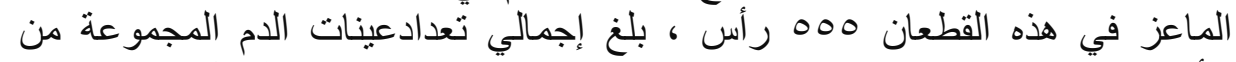

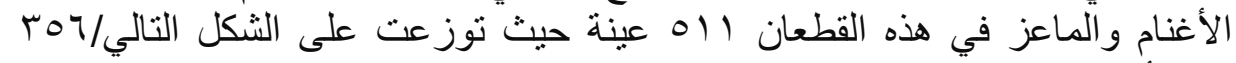

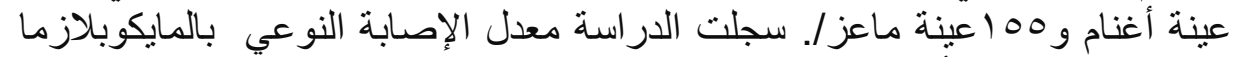

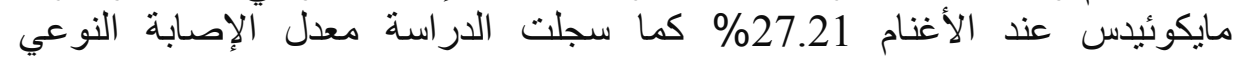

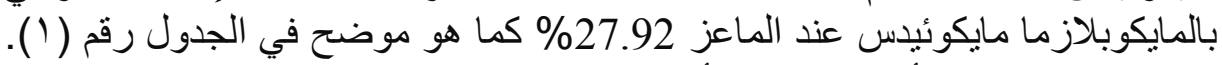

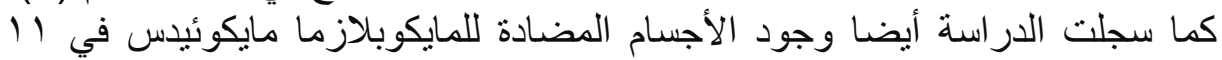

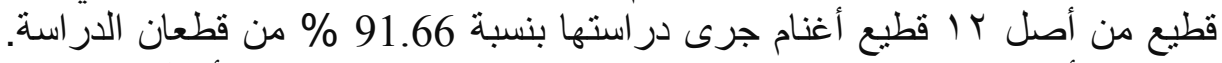

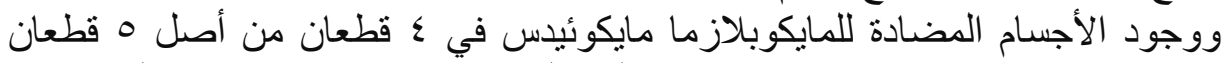

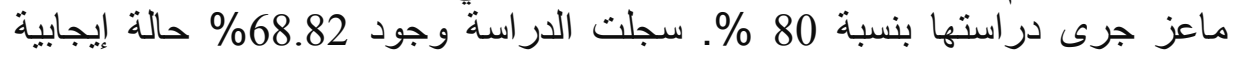

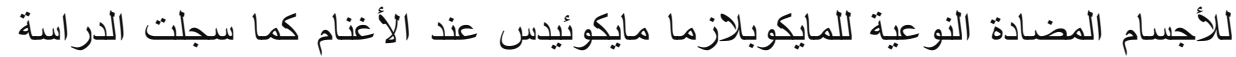

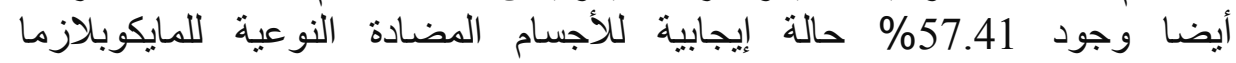

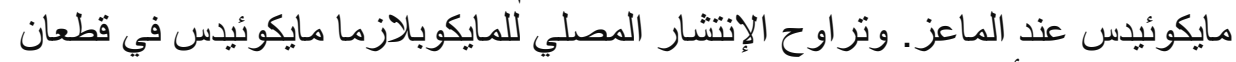

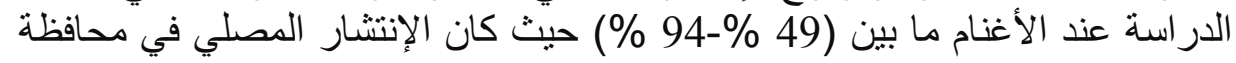

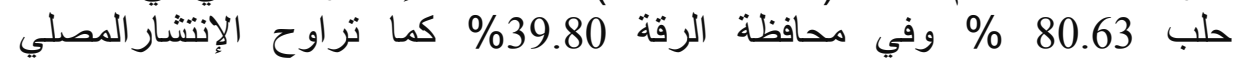

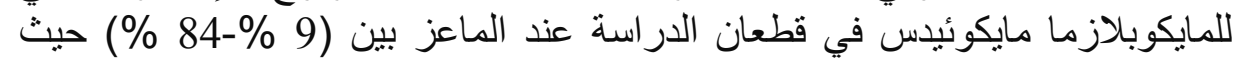

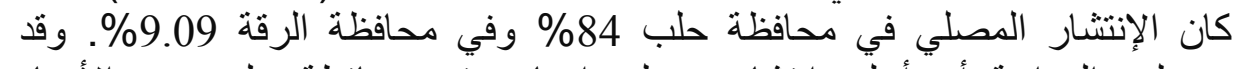

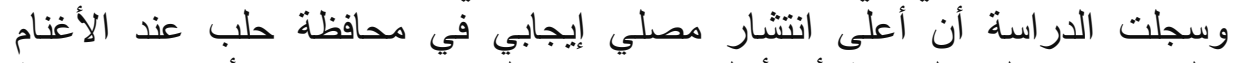

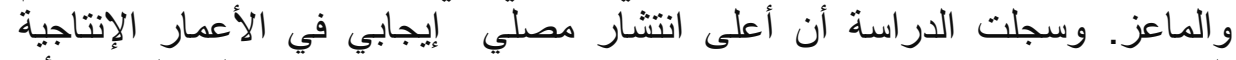

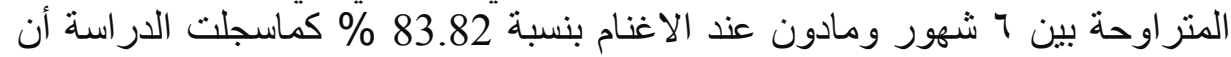

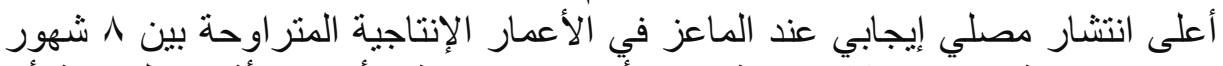

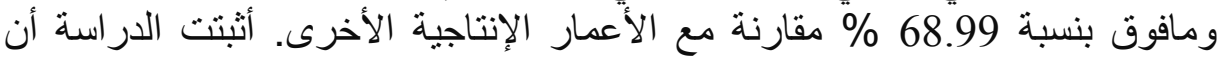


الإنتشار المصلي للحالات الإيجابية يزداد مع ازدياد حجم القطيع حيث انعدم الإنتشار

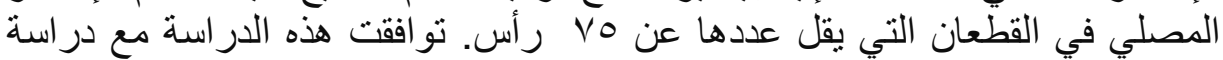
أجريت على ماعزفي شرق تركيا باستخدام تقنية تفاعل السلسلة

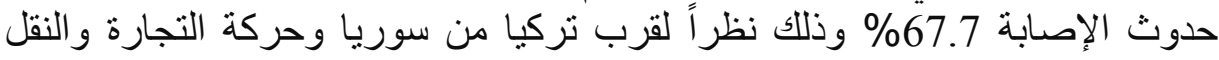

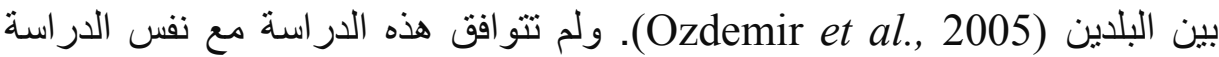

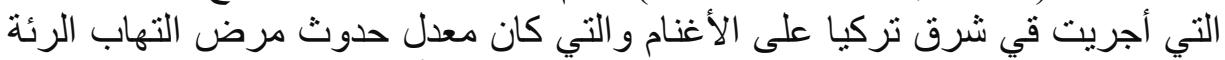

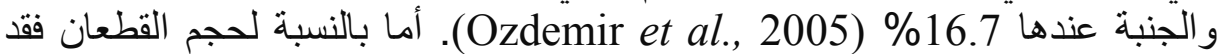

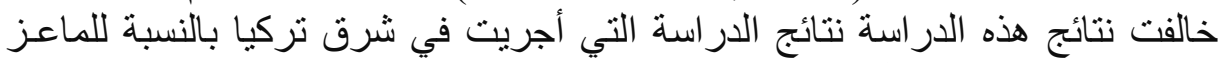

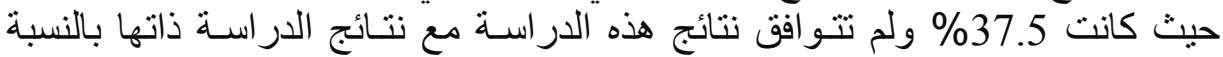

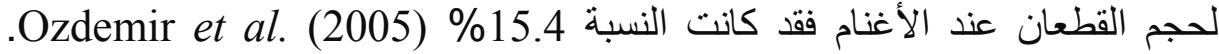

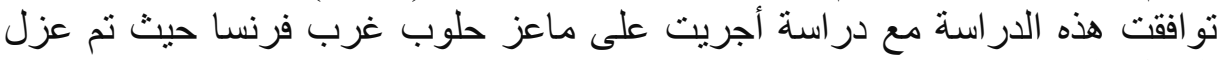

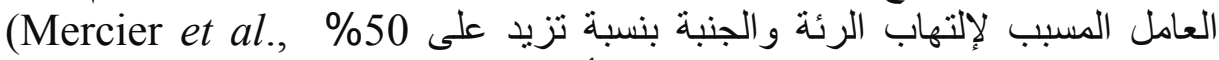

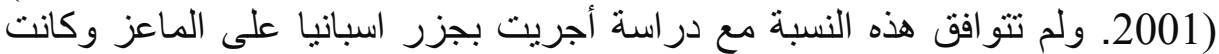

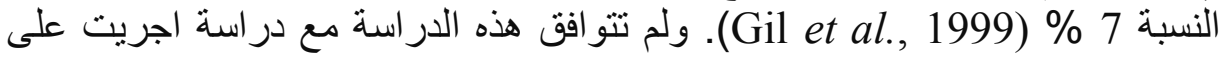

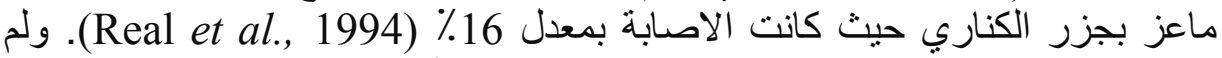

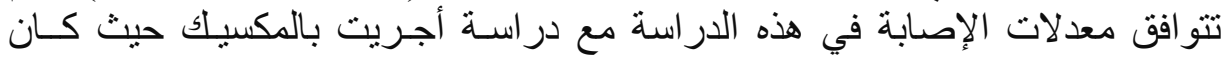

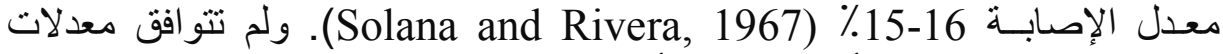

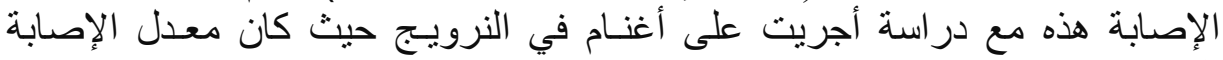

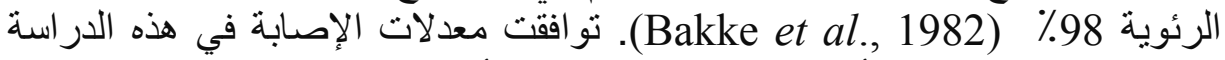

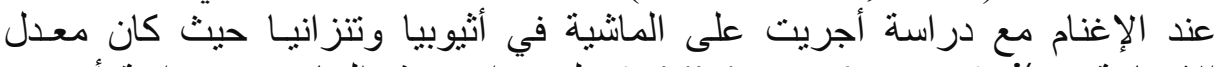

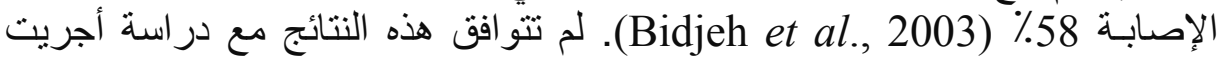

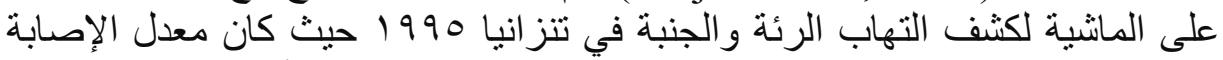

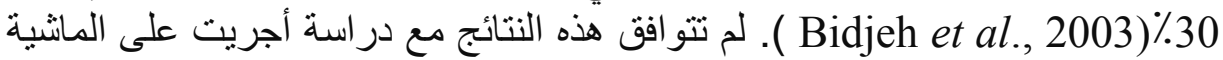

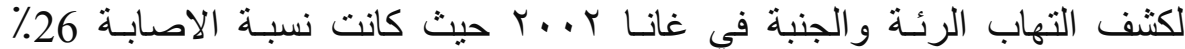
(Bidjeh et al., 2003)

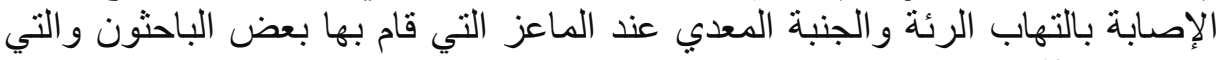
كانت . . (Kaliner and MacÖwan, 1976; Msami et al., 2001).

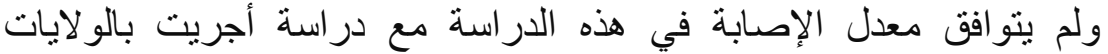

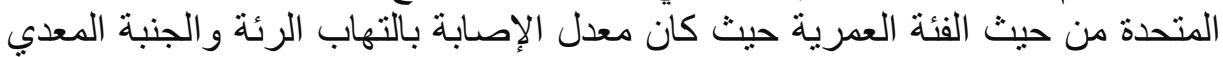

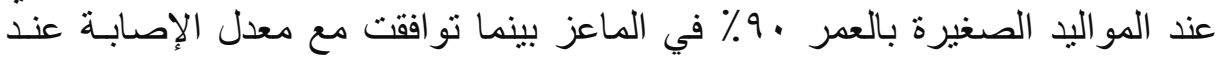

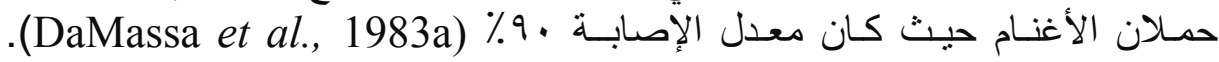

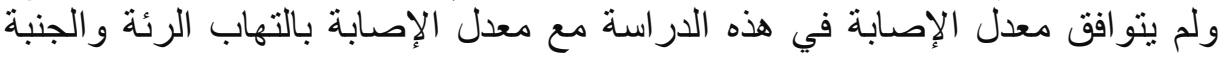

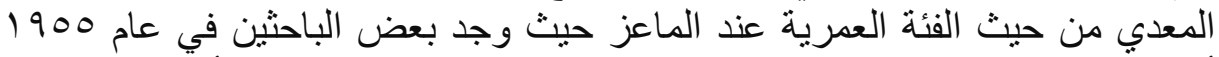

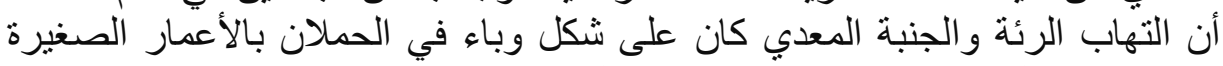
بينما يتو افق ذلك مع در استتا على الحملان الصغيرة (Cordy et al., 1955).

\section{REFERENCES}




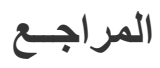

Bergonier, D.; Berthelot, X. and Poumarat, F. (1997): Contagious agalactia of small ruminants: current knowledge concerning epidemiology, diagnosis and control. Rev. Sci. Tech. 16: 848-873.

Bakke, T. and Nostvold, S. (1982): An investigation of ovine pneumonia in four herds from Central Norway. I. Prevalence of pneumonia and microbiological findings. Acta vet.scand., 23: 248-258.

Bidjeh, K. (2003): Analyse des stratégies de lutte contre la péripneumonie contagieuse bovine (PPCB) dans les pays membres du PACE. In Towards sustainable CBPP control programmes for Africa. Proc. FAO-OIE-AU/IBAR-IAEA Consultative Group on Contagious Bovine Pleuropneumonia, 3rd Meeting, 12-14 November, Rome. FAO, Rome, 201.

Cottew, G.5. (1979): Caprine-ovine mycoplasmas. In The Mycoplasmas, Vol. 2, pp. 103-132. Edited by J. G. Tully \& R. F.Whitcomb. London: Academic Press.

Conrad J. Krass and Max W. Gardner (1973): Etymology of the TermMy coplasma Int. J. of Syst. Bact.; 23, 1: 62-64.

Cordy, DR.; Adler, HE. and Yamamoto, R. (1955): A pathogenic pleuropneumonialike organism from goats. Cornell Vet. 45:5068.

DaMassa, AJ.; Brooks, DL. and Adler, HE. (1983a): Caprine mycoplasmosis:widespread infection in goats with Mycoplasma mycoides subsp. mycoides (large colony type). Am. J. Vet. Res. 44: 322-325.

Eaton, M.D.; Meiklejohn, G.; Van Herick, W. and Corey, M. (1945): Studies on the etiology of primary atypical pneumonia. J. Exp. Med. 82: 329-42.

Edward, DG. and Freundt, EA. (1956): "The classification and nomenclature of organisms of the pleuropneumonia group". J. Gen. Microbiol. 14 (1): 197-207.

Fisher, S.G. and Lerman, L.S. (1983): DNA fragments differing by single base-pair substitutions are separated in denaturing gradient gels: correspondence with theory. Proceedings of the National Academy of Sciences USA 80: 1579-1583.

Goodburn, G.M. and Marmion, B.P. (1962): Investigations of the nature of Eaton's primary atypical pneumonia organism. J. Hyg. Epidemiol. Microbiol. Immunol. 6: 176-82. 
Gil, M.C.; Hermosa De Mendoza, M.; Rey, J.; Alonso, J.M.; Poveda, J.B. and Hermosa De Mendoza, J. (1999): Aetiology of caprine contagious agalactia syndrome in Extremudura, Spain. Veterinary Record 144: 24-25.

Harwick, H.J.; Kalmanson, G.M. and Guze, L.B. (1972): Human diseases associated with mycoplasmas. Calif. Med. 116: 1-7.

Hutcheon, D. (1889): Contagious pleuropneumonia in goats at Cape Colony, South Africa.Veterinary Journal 29: 399-404

Kaliner, G. and MacOwan, KJ. (1976): The pathology of experimental and natural contagious caprine pleuropneumonia in Kenya. Zentralbl. Veterinarmed. (B), 23: 652-661.

Lerman, L.S. and Beldjord, C. (1999): Comprehensive mutation detection with denaturing gradient gel electrophoresis. In: Cotton, R.G.H., Edkins, E. and Forrest, S. (eds) Mutation Detection. Oxford University Press, Inc., New York, pp. $35-61$.

Leach, R.H.; Ernø, H. and Mac Owan, K.J. (1993): Proposal for designation of F38-type caprine mycoplasmas as Mycoplasma capricolum subsp. Capripneumoniae subsp. nov. and consequent obligatory relegation of strains currently classified as M. capricolum (Tully, Barile, Edward, Theodore, and Erno 1974) to an additional new subspecies, M. capricolum subsp. Capricolum subsp. nov. Int. J. Syst. Bacteriol. 43: 603-605.

Lefevre, P.-C.; Jones, G.E. and Ojo, M.O. (1987): Les mycoplasmoses pulmonaires des petits ruminants. Mycoplasmoses of ruminants. Revue Scientifi que et Technique. Office International des Epizooties 6: 713-757.

Msami, HM.; Kapaga, AM.; Heldtander, M. and Bölske, G. (2001): Contagious caprine pleuropneumonia in Tanzania. Vet. Rec. 148: 22-23.

Mercier, P.; Lenfant, D.; Poumarat, F. and Perrin, G. (2001): Prevalence of mycoplasmal infection within French milking caprine herds In: Poveda, J.B., Fernandez, A., Frey, J. and Johnansson, K.-E. (eds) Mycoplasmas of Ruminants: Pathogenicity, Diagnostics, Epidemiology and Molecular Genetics, Vol. 5. European Commission, Brussels, pp. 130-133.

Nayak, N.C. and Bhowmik, M.K. (1990): Goat fl ea (order Siphonaptera) as a possible vector for the transmission of caprine 
mycoplasmal polyarthritis with septicaemia. Preventive Veterinary Medicine 9: 259-266.

Newton, L.G. (1992): Contagious bovine pleuropneumonia in Australia: some historic highlights from entry to eradication. Australian Veterinary Journal 69: 306-317.

Nocard, E.; Roux, E.; Borrel, A.; Salimbeniet, T. and DujardinBeaumetz, E. (1896): Le Microbe de la Peripneumonie. Annales de l'Institut Pasteur. 12: 240-62. Translation: W.

Ozdemir, U.; Ozdemir, S.; March, J.; Churchwood, C. and Nicholas, R.A.J. (2005): Outbreaks of CCPP in the Thrace region of Turkey. Veterinary Record 156: 286-287.

Perrin, J.; Muller, M.; Zangger, N. and Nicolet, J. (1994): Infection a Mycoplasma mycoides subsp.mycoides LC chez des cabris bezoard (Capra aegagrus cretica) au jardin zoologique de Berne. Schweizer Arch. Tierheilk. 136: 270-274.

Real, F.; Deniz, S.; Acosta, B.; Ferrer, O. and Poveda, J.B. (1994): Caprine contagious agalactia caused by Mycoplasma agalactiae in the Canary Islands. Veterinary Record 135: 15-16.

Rodriguez, F.; Ball, H.J.; Finlay, D.; Campbell, C. and Mackie, D.P. (1996a): Detection of Mycoplasma mycoides subspecies mycoides by monoclonal antibody-based sandwich ELISA. Veterinary Microbiology 51: 69-76.

Rosendal, S.; Erno, H. and Wyand, D.S. (1979): Mycoplasma mycoides subsp. mycoides as a cause of polyarthritis in goats. Journal of the American Veterinary Medical Association 175: 378-380

Solana, P. and Rivera, E. (1967): Infection of goats in Mexico by Mycoplasma mycoides var. capri. Ann. N.Y. Acad. Sci., 143: 357-363.

Smith, M.C. and Sherman, D.M. (1994): Bacterial diseases. In: Goat Medicine. Lea and Febiger, Philadelphia, USA, p. 86.

Tola, S.; Angioi, A.; Rocchigiani, A.M.; Idini, G.; Manunta, D.; Galleri, G. and Leori, G. (1997): Detection of Mycoplasma agalactiae in sheep milk samples by polymerase chain reaction. Veterinary Microbiology 54: 17-22.

Thiaucourt, F. and Bölske, G. (1996): Contagious caprine pleuropneumonia and other pulmonary mycoplasmoses of sheep and goats. Rev. Sci. Tech. 15: 1397-1414. 
Assiut Vet. Med. J. Vol. 58 No. 132 January 2012

Ter Laak, E.A. (1992): Contagious bovine pleuropneumonia: a review. VetQ 14: 104-110. 